\title{
Enhancement of Mechanical and Thermal Properties of Polylactic Acid/Polycaprolactone Blends by Hydrophilic Nanoclay
}

\author{
Chern Chiet Eng, ${ }^{1}$ Nor Azowa Ibrahim, ${ }^{1}$ Norhazlin Zainuddin, ${ }^{1}$ Hidayah Ariffin, ${ }^{2}$ \\ Wan Md. Zin Wan Yunus, ${ }^{3}$ Yoon Yee Then, ${ }^{1}$ and Cher Chean Teh ${ }^{1}$ \\ ${ }^{1}$ Department of Chemistry, Faculty of Science, University Putra Malaysia, 43400 UPM Serdang, Selangor, Malaysia \\ ${ }^{2}$ Department of Bioprocess Technology, Faculty of Biotechnology and Biomolecular Sciences, University Putra Malaysia, \\ 43400 UPM Serdang, Selangor, Malaysia \\ ${ }^{3}$ Chemistry Department, Centre for Defence Foundation Studies, National Defence University of Malaysia, Kem Sungai Besi, \\ 57000 Kuala Lumpur, Malaysia
}

Correspondence should be addressed to Nor Azowa Ibrahim; norazowa@science.upm.edu.my

Received 28 August 2013; Accepted 19 November 2013

Academic Editors: M. Jayachandran and M. Romero Pérez

Copyright (C) 2013 Chern Chiet Eng et al. This is an open access article distributed under the Creative Commons Attribution License, which permits unrestricted use, distribution, and reproduction in any medium, provided the original work is properly cited.

\begin{abstract}
The effects of hydrophilic nanoclay, Nanomer PGV, on mechanical properties of Polylactic Acid (PLA)/Polycaprolactone (PCL) blends were investigated and compared with hydrophobic clay, Montmorillonite K10. The PLA/PCL/clay composites were prepared by melt intercalation technique and the composites were characterized by X-ray Diffraction (XRD), Fourier Transform Infrared Spectroscopy (FTIR), Thermogravimetric Analysis (TGA), Dynamic Mechanical Analysis (DMA), Scanning Electron Microscopy (SEM), and Transmission Electron Microscopy (TEM). FTIR spectra indicated that formation of hydrogen bond between hydrophilic clay with the matrix. XRD results show that shifting of basal spacing when clay incorporated into polymer matrix. TEM micrographs reveal the formation of agglomerate in the composites. Based on mechanical properties results, addition of clay Nanomer PGV significantly enhances the flexibility of PLA/PCL blends about $136.26 \%$. TGA showed that the presence of clay improve thermal stability of blends. DMA show the addition of clay increase storage modulus and the presence of clay Nanomer PGV slightly shift two $T_{g}$ of blends become closer suggest that the presence of clay slightly compatibilizer the PLA/PCL blends. SEM micrographs revealed that presence of Nanomer PGV in blends influence the miscibility of the blends. The PLA/PCL blends become more homogeneous and consist of single phase morphology.
\end{abstract}

\section{Introduction}

Petroleum-based polymers such as polypropylene (PP), polyethylene (PE), and polystyrene (PS) cause major drawback to environment as these polymers tend to accumulate in disposal system due to these polymers are nondegradable. Therefore, biodegradable polymer attracted the attention of researcher as biodegradable polymer seems to be the best solution to this problem. A wide range of natural or synthetic polymers degrade by hydrolytic (polyglycolide, polylactides, polydioxanone, Polycaprolactone, polyhydroxyalkanoates) or enzymatic (polysaccharides, protein, polyamino acids) route [1]. Although these polymers have wide range of mechanical properties and degradation rate, inappropriate stiffness or degradation rate restrict their application, therefore, blending with other polymers, copolymerization or adding plasticizer can be used to tune the properties of these polymers according to application requirements [2].

Polylactic acid (PLA) is biodegradable polymer produced from renewable resources as PLA is obtained from polymerization of lactic acid monomer, a fermentation product obtained from corn starch by bacterial fermentation [3]. PLA has good mechanical properties, thermal plasticity, and biocompatibility. However, PLA is a comparatively brittle and stiff polymer with low deformation at break. Therefore, 
modification of PLA is needed in order to compete with other flexible polymers such as polypropylene or polyethylene [4]. There are many techniques to modify PLA such as copolymerization $[5,6]$, blending with other polymers $[7,8]$, the addition of plasticizers [9], the addition of nucleating agents [10], and forming composites with fiber or nanoparticles $[11,12]$.

Polycaprolactone (PCL) is biodegradable polymer from nonrenewable petrochemical resources which prepared by ring opening polymerization of $\varepsilon$-caprolactone using variety of anionic, cationic, and co-ordination catalysts. PCL can also obtain from free radical ring opening polymerization of 2-methylene-1-3-dioxepane. PCL is flexible semicrystalline polymer with low melting point and exceptional blendcompatibility. Therefore, PCL can be blended with other polymers to improve stress crack resistance, dye-ability, and adhesion [13]. High flexibility PCL can be considered as a good plasticizer for PLA compared to low molecular weight plasticizers as it does not migrate to the surface of the blended samples and the physical properties cannot be debased [14].

However, due to immiscibility of PLA/PCL blend [15], compatibilization is needed to improve its properties. Tuba et al. compatibilized PLA/PCL with L-lysine-diisocyanate and L-lysine-triisocyanate which enhance the fracture toughness, changes the morphology of fracture surface become more homogeneous and also promote crystallization and heterogeneous nucleation of PLA [16]. Hoidy et al. incorporate octadecylamine-montmorillonite (ODA-MMT) and fatty hydroxamic acid-montmorillonite (FHA-MMT) in PLA/PCL blend and the results revealed that addition of clay improve mechanical properties and also thermal stability of the blends [17].

The objective of this paper is to investigate the effect of addition two type of clay which is hydrophobic Montmorillonite K10 and hydrophilic Nanomer PGV on mechanical properties and thermal properties of PLA/PCL blend by melt intercalation. Various characterization techniques such as X-ray Diffraction (XRD), Fourier Transform Infrared Spectroscopy (FTIR), Thermogravimetric Analysis (TGA), Dynamic Mechanical Analysis (DMA), Scanning Electron Microscopy (SEM), and Transmission Electron Microscopy (TEM) used to study the effect of addition of clay on the properties of PLA/PCL blend.

\section{Experimental}

2.1. Materials. All reactions were carried out by using reagent grade chemicals (>98\% purity) without further purification. The clay Montmorillonite K10 and Nanoclay, hydrophilic bentonite (Nanomer PGV) was purchased from Sigma-Aldrich and used as received. Polylactide Resin 4060D was supplied by NatureWorks while Polycaprolactone (CAPA 650) was supplied by Solvay Caprolactone.

2.2. Preparation of PLA/PCL/Clay Nanocomposites. The nanocomposite was prepared by melt blending technique. The composition of PLA and PCL kept constant at $85 \mathrm{wt} \%$ and $15 \mathrm{wt} \%$, respectively, while the clay content was varied between 0 to $7 \mathrm{wt} \%$. PLA, PCL and clay were manually premixed in a container and fed into Brabender Plastograph
$\mathrm{EC}$ at $170^{\circ} \mathrm{C}$ with rotor speed of $50 \mathrm{rpm}$ for 10 minutes. The products were then compression moulded into sheets of $1 \mathrm{~mm}$ (for tensile properties) or $3 \mathrm{~mm}$ (for flexural properties and izod impact resistance) thickness by an electrically heated hydraulic press with a force of $1500 \mathrm{kN}$ at $160^{\circ} \mathrm{C}$ for 10 minutes. The sample sheets were then used for further characterization.

2.3. Fourier Transform Infrared Spectroscopy (FTIR). Perkin Elmer Spectrum 100 series spectrometer equipped with attenuated total reflectance (ATR) was used to determine the functional groups and types of the bonding of the samples. The infrared spectra were recorded in the range of frequency of 280 to $4000 \mathrm{~cm}^{-1}$.

2.4. X-Ray Diffraction (XRD). X-Ray Diffraction measurement to determine the $d$-spacing of the clay was carried out by using X'PERT PRO PW3040 where Cu K $\alpha(\lambda=1.5406 \AA)$ beam operated at $40 \mathrm{~mA}$ and $45 \mathrm{kV}$ with the data recorded in $2 \theta$ range of $2^{\circ}$ to $10^{\circ}$ using the scan rate of $2^{\circ} / \mathrm{min}$.

2.5. Transmission Electron Microscope (TEM). The Transmission Electron Micrographs of the thin layer of the nanocomposites were recorded by Hitachi H-7100 TEM which operated at an accelerating voltage of $100 \mathrm{kV}$. The thin layer of samples was prepared by using a Reichert Jung Ultracut E microtome equipped with cryosectioning unit whereas the samples were sliced into thin layer of about $90 \mathrm{~nm}$ by a diamond knife cooled at $-120^{\circ} \mathrm{C}$ with liquefied nitrogen.

2.6. Tensile Properties. Tensile properties were measured with Instron machine model 4301, with grip attachment distance of $45 \mathrm{~mm}$. Load of $1.0 \mathrm{kN}$ was applied at constant crosshead speed of $5 \mathrm{~mm} \mathrm{~min}^{-1}$. Data was processed with computerized Instron (Software series 9, national instruments GPIB PC2/2a and NI-488.2). Test specimen were prepared and stamped in accordance to ASTM D638 dumbbell parameters. Sample thickness was measure with Mitutoyo Digimatic Indicator, type IDF-112, having measuring accuracy of $\pm 0.001 \mathrm{~mm}$.

2.7. Flexural Properties. The flexural strength and flexural modulus were measured with Instron Universal Testing Machine 4301 according to ASTM D790. The size of the samples testing is $127 \mathrm{~mm} \times 12.7 \mathrm{~mm} \times 3 \mathrm{~mm}$. The crosshead speed is $1.3 \mathrm{~mm} / \mathrm{min}$ and the support span length is $48 \mathrm{~mm}$. Data was processed with computerized Instron (Software series 9, national instruments GPIB PC2/2a and NI-488.2).

2.8. Izod Impact Resistance. The Izod impact test was carried out according to ASTM D256 standard using an impact tester (IZOD Impact Tester). The sample size is $63.5 \times 12.7 \times 3 \mathrm{~mm}$, while the notch length is $2.54 \mathrm{~mm}$. The energy required to break the samples was divided by unit area of residual crosssection of sample to obtain impact resistance value. The impact strength $(\mathrm{J} / \mathrm{m})$ was calculated by dividing the energy obtained (J) with the thickness of specimen (m). 


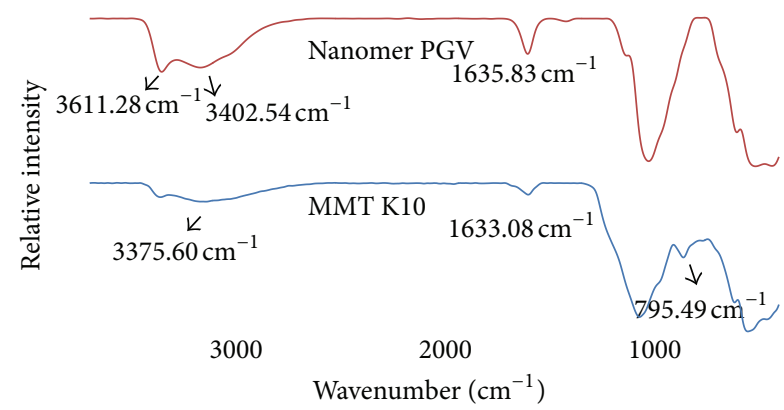

FIGURE 1: FTIR spectra of Montmorillonite K10 and Nanomer PGV.

2.9. Thermogravimetric Analysis (TGA). Perkin Elmer TGA7 was used for Thermogravimetic Analysis of samples where the mass of samples about $15 \mathrm{mg}$ and were heated from $35^{\circ} \mathrm{C}$ to $800^{\circ} \mathrm{C}$ with the heating rate of $10^{\circ} \mathrm{C} / \mathrm{min}$. Nitrogen gas was pumped with the flow rate of $20 \mathrm{~mL} / \mathrm{min}$ in order to let the analysis carry out in nitrogen atmosphere.

2.10. Dynamic Mechanical Analysis (DMA). Dynamic Mechanical Analyzer Perkin Elmer Model Pyris Diamond DMA was used. Samples were tested under the condition of static force $10 \mathrm{~N}$, dynamic force $8 \mathrm{~N}$ with $1 \mathrm{~Hz}$ frequencies. Scan was done from $-100^{\circ} \mathrm{C}$ to $130^{\circ} \mathrm{C}$ at $2^{\circ} \mathrm{C} / \mathrm{min}$ rate with sample dimensions were $1 \mathrm{~mm}$ thickness and $30 \mathrm{~mm}$ length by using bending mode.

2.11. Scanning Electron Microscopy (SEM). The surface morphology of fracture surfaces of tensile test specimen was observed with Scanning Electron Microscope JEOL JSM-6400 with the samples were sputter coated with gold using Bio-rad coating system before viewing.

\section{Results and Discussion}

\subsection{Characterization of Clay}

3.1.1. Fourier Transform Infrared Spectroscopy (FTIR). FTIR spectra of Montmorillonite K10 and Nanomer PGV are shown in Figure 1. The presence of broad band at $3611.28 \mathrm{~cm}^{-1}$ for Nanomer PGV shows that the presence of free water molecule vibration as $\mathrm{H}-\mathrm{O}-\mathrm{H}$ stretching of water molecules present in the interlayer region of clay which indicates that Nanomer PGV is hydrophilic. However, FTIR spectra indicates that Montmorillonite K10 is hydrophobic as the intensity of free $\mathrm{O}-\mathrm{H}$ stretching peak is low. Band at $1633.08 \mathrm{~cm}^{-1}$ and $1635.83 \mathrm{~cm}^{-1}$ for Montmorillonite $\mathrm{K} 10$ and Nanomer PGV correspond to $\mathrm{OH}$ deformation of water [18]. Besides, a unique characteristic peak at $795.49 \mathrm{~cm}^{-1}$ for Montmorillonite K10 correspond to quartz symmetrical stretching as mention by Ravisankar et al. [19] indicates the presence of quartz in the clay. Montmorillonite K10 and Nanomer PGV exhibits similar peak correspond to $\mathrm{O}-\mathrm{H}$ stretching $\left(3375.60 \mathrm{~cm}^{-1}\right.$ and $\left.3402.54 \mathrm{~cm}^{-1}\right), \mathrm{Si}-\mathrm{O}$ stretching (1032.23 and $982.78 \mathrm{~cm}^{-1}$ ) and $\mathrm{Si}-\mathrm{O}$ bending (447.28 and $406.15 \mathrm{~cm}^{-1}$ ), respectively.

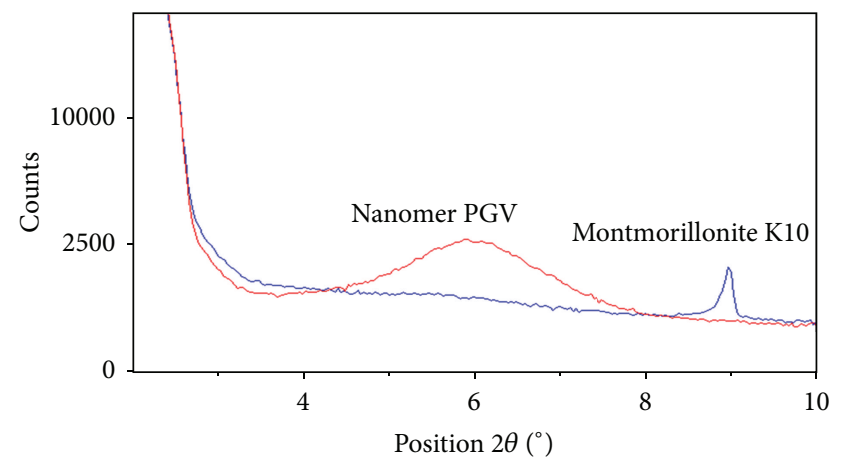

FIGURE 2: XRD patterns of Montmorillonite K10 and Nanomer PGV.

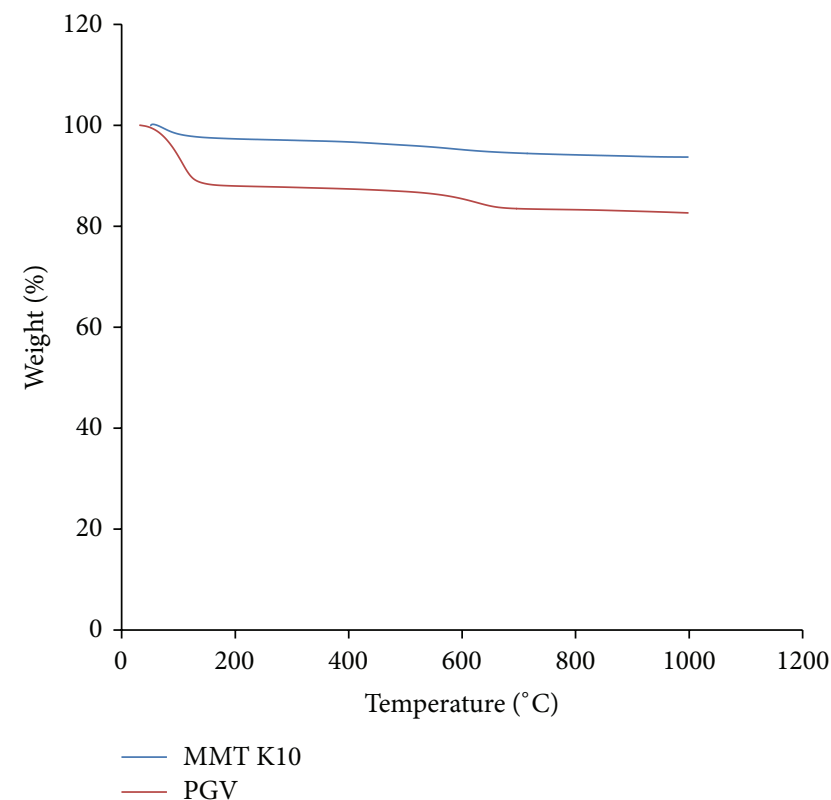

FIGURE 3: TG thermogram of Montmorillonite K10 and Nanomer PGV.

TABLE 1: Basal spacing of Montmorillonite K10 and Nanomer PGV.

\begin{tabular}{lcc}
\hline Clay & $2 \theta\left(^{\circ}\right)$ & Basal spacing $(\mathrm{nm})$ \\
\hline Montmorillonite K10 & 8.967 & 0.985 \\
Nanomer PGV & 6.043 & 1.461 \\
\hline
\end{tabular}

3.1.2. X-Ray Diffraction (XRD). The XRD patterns of clays are illustrated in Figure 2. Montmorillonite K10 has $0.985 \mathrm{~nm}$ of basal spacing at $2 \theta=8.967^{\circ}$ while Nanomer PGV has higher value of basal spacing which is $1.461 \mathrm{~nm}$ at $2 \theta=6.043^{\circ}$. The value of $2 \theta$ and basal spacing of clays are summarized in Table 1 .

3.1.3. Thermogravimetric Analysis (TGA). The TG and DTG thermogram of clay Montmorillonite K10 and Nanomer PGV are shown in Figures 3 and 4, respectively. Decomposition of both clays shows two thermal decomposition steps. The first step is desorption of water from interlayer space which around $200^{\circ} \mathrm{C}$. Clay Nanomer PGV shows the percentage of 


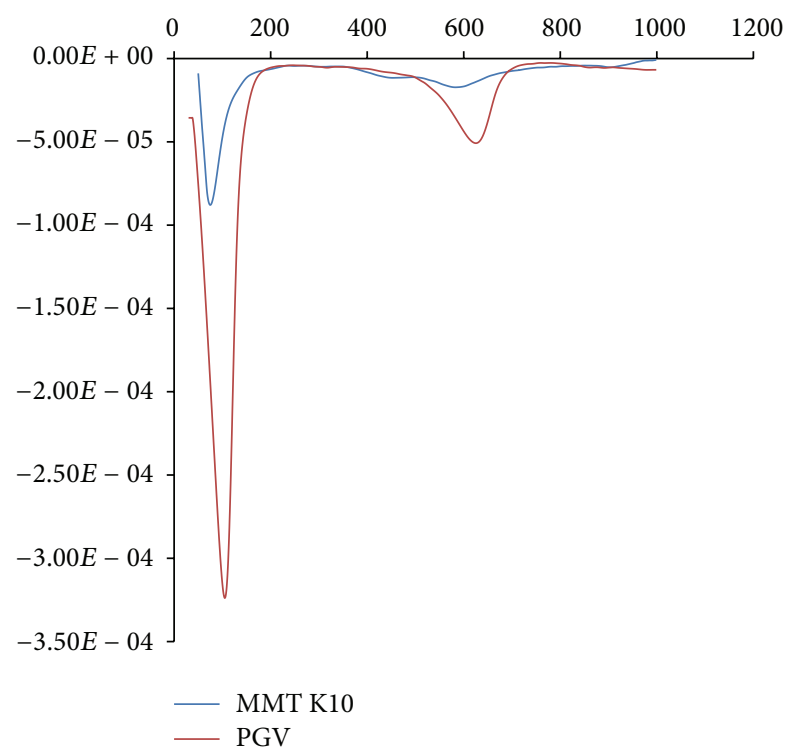

FIGURE 4: DTG thermogram of Montmorillonite K10 and Nanomer PGV.

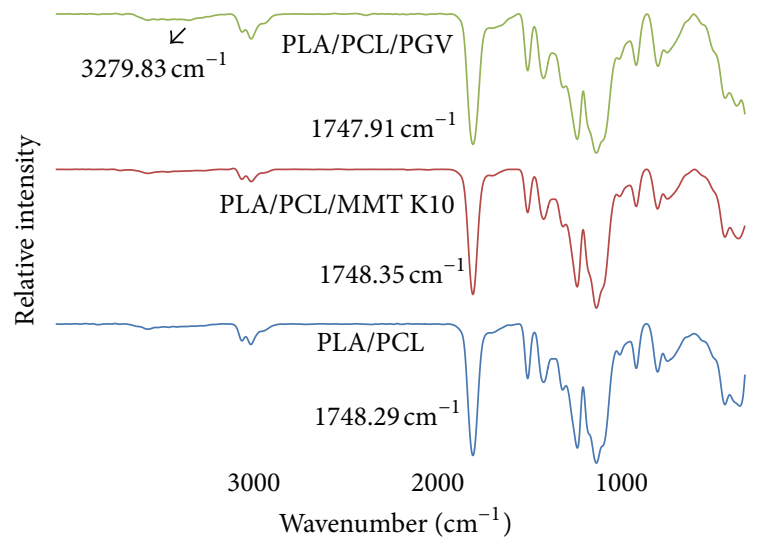

FIGURE 5: FTIR spectra of PLA/PCL/1 wt\% clay composites.

weight loss (11.8\%) higher than Montmorillonite K10 (3\%) during the first degradation steps which proved that Clay Nanomer PGV is more hydrophilic than Montmorillonite K10. The second step is dehydroxylation of the layer crystal lattice structure which around $700^{\circ} \mathrm{C}$ [20]. The percentage of weight loss for Montmorillonite K10 and Nanomer PGV at this stage is $2.9 \%$ and $3.9 \%$ respectively.

\subsection{Characterization of PLA/PCL/Clay Composites}

3.2.1. Fourier Transform Infrared Spectroscopy (FTIR). Figure 5 shows the infrared spectra of PLA/PCL and PLA/PCL/1 wt\% clay composites. The spectra shows that all three composites exhibited strong absorbance peak around $1748 \mathrm{~cm}^{-1}$ which correspond to the vibration of carbonyl group, $\mathrm{C}=\mathrm{O}$ stretching. Peak at $3279.83 \mathrm{~cm}^{-1}$ indicated hydrogen bonded $\mathrm{O}-\mathrm{H}$ stretching present at PLA/ PCL/Nanomer PGV composites which suggest that some hydrogen bond formed between hydrophilic clay with the

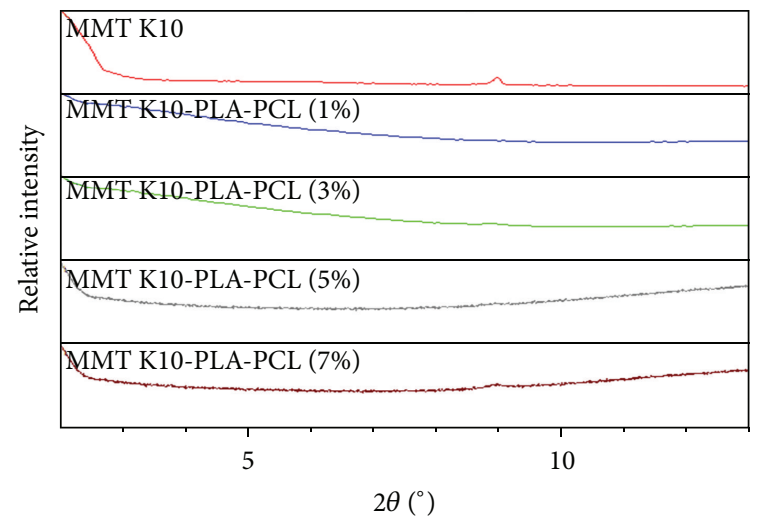

FIGURE 6: XRD patterns of Montmorillonite K10 and PLA/PCL composites at different clay loadings.

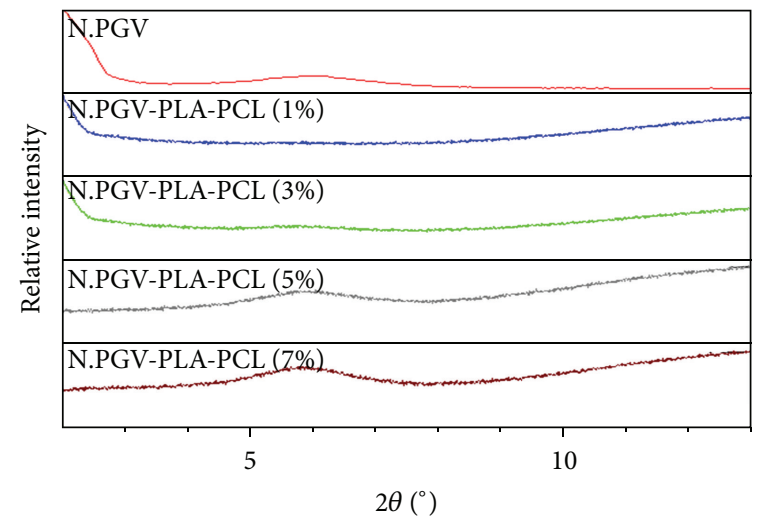

FIGURE 7: XRD patterns of Nanomer PGV and PLA/PCL composites at different clay loadings.

matrix. This might due to PLA consists of $\mathrm{OH}$ bond at the end of the polymer chain which can form hydrogen group with the hydrophilic clay.

3.2.2. X-Ray Diffraction (XRD). Figure 6 shows the XRD pattern of Montmorillonite K10 and PLA/PCL/Montmorillonite K10 composites at different clay loading. For Montmorillonite $\mathrm{K} 10$, the basal spacing of composites with clay loading of $1 \mathrm{wt} \%$ to $5 \mathrm{wt} \%$ could not be detected which might due to low clay content in composites or absence of any ordered layer structure as the result of exfoliation and random distribution of the clay platelets within polymer blend. Generally, exfoliated system is more feasible with lower clay content while intercalated system more frequently observed for nanocomposites with higher clay content [21]. The diffraction angle of Montmorillonite K10 is shifted from $8.967^{\circ}(0.985 \mathrm{~nm})$ to $8.855^{\circ}(0.998 \mathrm{~nm})$ for $7 \mathrm{wt} \%$ of Montmorillonite K10 in PLA/PCL blends.

The XRD pattern of Nanomer PGV and PLA/PCL/ Nanomer PGV composites at different clay loading illustrated in Figure 7. The basal spacing of Nanomer PGV increase from $1.461 \mathrm{~nm}(6.043 \circ)$ to $1.532 \mathrm{~nm}\left(5.765^{\circ}\right), 1.564 \mathrm{~nm}\left(5.645^{\circ}\right)$ and $1.584 \mathrm{~nm}\left(5.575^{\circ}\right)$ when $3 \mathrm{wt} \%, 5 \mathrm{wt} \%$ and $7 \mathrm{wt} \%$ of clay added into polymer blends, respectively. All basal spacing 


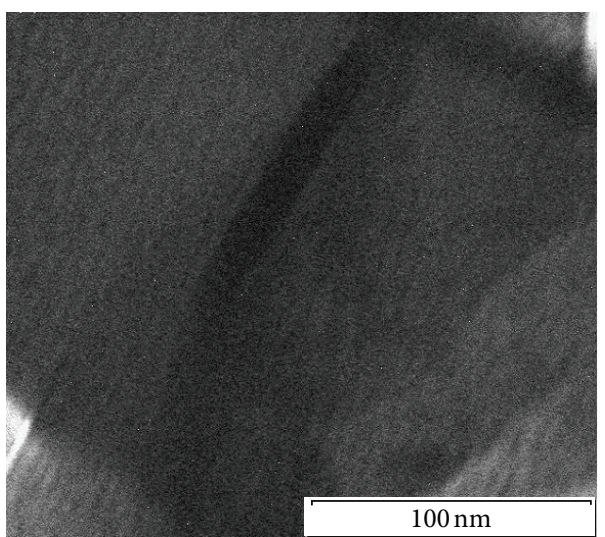

(a)

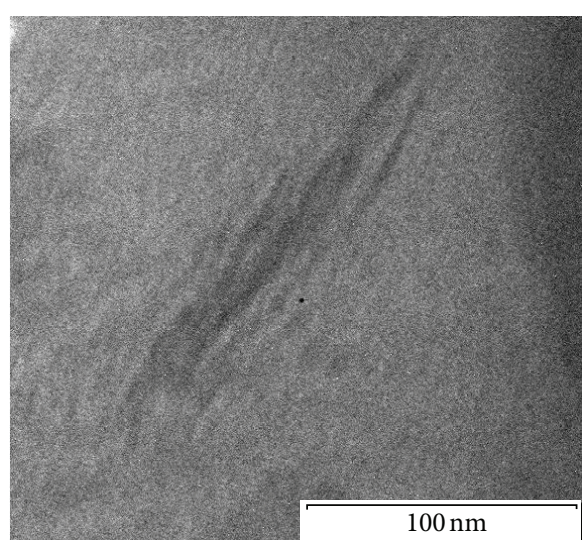

(b)

FIgURE 8: TEM micrographs of (a) PLA/PCL/1 wt\% Montmorillonite K10 and (b) PLA/PCL/1 wt\% Nanomer PGV.

TABLE 2: Basal spacing of PLA/PCL composites at various clay loadings.

\begin{tabular}{lcc}
\hline Sample & $2 \theta\left(^{\circ}\right)$ & Basal spacing $(\mathrm{nm})$ \\
\hline Clay MMT K10 & 8.967 & 0.985 \\
PLA/PCL/1 wt\% MMT K10 & - & - \\
PLA/PCL/3 wt\% MMT K10 & - & - \\
PLA/PCL/5 wt\% MMT K10 & - & - \\
PLA/PCL/7 wt\% MMT K10 & 8.855 & 0.998 \\
\hline Clay N.PGV & 6.043 & 1.461 \\
PLA/PCL/1 wt\% N.PGV & - & - \\
PLA/PCL/3 wt\% N.PGV & 5.765 & 1.532 \\
PLA/PCL/5 wt\% N.PGV & 5.645 & 1.564 \\
PLA/PCL/7 wt\% N.PGV & 5.575 & 1.584 \\
\hline
\end{tabular}

of Montmorillonite K10 and Nanomer PGV composites are summarized at Table 2 . The increase of the basal spacing of the composites compared to the corresponding neat clay indicated that the PLA/PCL chains were intercalated into the clay matrix during melt intercalation. The peak of clay present in the composites confirms the formation of composites.

3.2.3. Transmission Electron Microscope (TEM). The Transmission Electron Micrograph of (a) PLA/PCL/1 wt\% Montmorillonite K10 and (b) PLA/PCL/1 wt\% Nanomer PGV is shown in Figure 8. The dark area represents the intercalated clay layers. Montmorillonite K10 (Figure 8(a)) agglomerates tend to form throughout polymer matrix which inhibits good surface contact between polymer and clay as the incomplete dispersal of reinforcing phase in composites [22]. Therefore, phase separated microcomposites is formed. This observation support the XRD result which shows little shifting of diffraction peak of Montmorillonite K10 in PLA/PCL/Montmorillonite K10 composites. Nanomer PGV (Figure 8(b)) also form agglomerates in PLA/PCL matrix. The result of XRD show increment of basal spacing when clay is added into matrix which suggest that the possibility of the formation of intercalated type nanocomposites, but there is

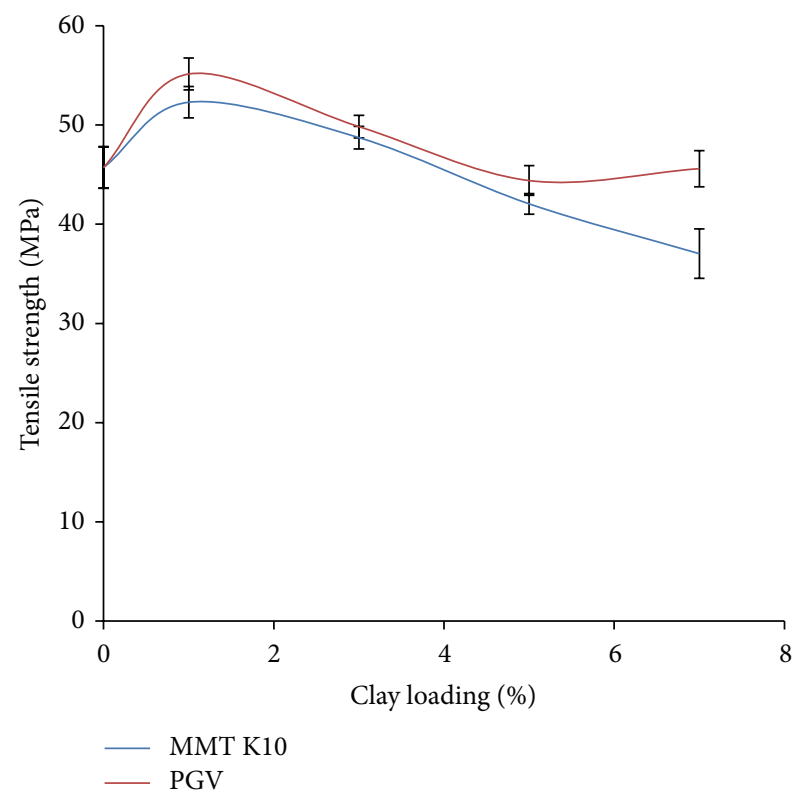

FIGURE 9: Tensile strength of PLA/PCL/clay nanocomposites.

no direct evidence proof that the formation nanocomposites from TEM micrographs.

3.2.4. Tensile Properties. The tensile strength of PLA/PCL/ clay composites is shown in Figure 9. When 1\% of clay Montmorillonite K10 and Nanomer PGV added into the blends, the tensile strength increase about $13.82 \%(52.29 \mathrm{MPa})$ and $16.89 \%(55.14 \mathrm{MPa})$, respectively, compared to the unfilled PLA/PCL blends (45.74 MPa). On the other hand, when higher amount of clay added into the blends, the tensile strength decrease gradually. When small amount of clay added into polymer matrix, the clay is located in the interphase between the matrix and the dispersed phase. Besides, incorporation of clay increase interfacial adhesion, thus compatibilization at a molecular level is achieved which improves stress transfer within composites and then cause tensile strength increase [23]. However, further increase the clay content 


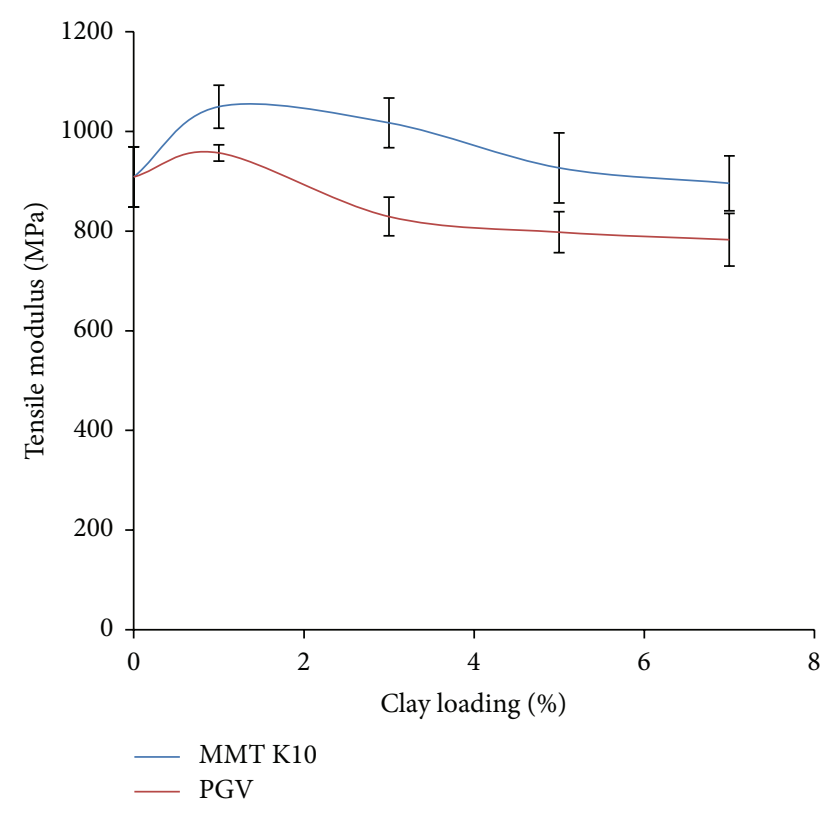

Figure 10: Tensile modulus of PLA/PCL/clay nanocomposites.

decrease the tensile strength as part of the clay located in the interfacial area while the excess clay is dispersed in the matrix which cause decrease in homogeneity and formation of agglomeration which decrease the tensile strength [24].

Figure 10 shows the effect of clay loading on the tensile modulus of PLA/PCL blends. The tensile modulus of PLA/PCL blends increases from 908.57 MPa to $1049.67 \mathrm{MPa}$ when $1 \mathrm{wt} \%$ Montmorillonite K10 is added while the addition of $1 \mathrm{wt} \%$ Nanomer PGV increases tensile modules of blends from 908.57 MPa to $956.85 \mathrm{MPa}$. The tensile modulus decreases when higher amount of clay is added. Montmorillonite silicate has been found to be efficient in stiffening polymers [25]. As high-aspect ratio of clay (1 $\mathrm{wt} \%)$, the surface area exposed to the polymer is huge and the region of the polymer matrix is physisorbed on the silicate surface, thus stiffened through its affinity for and adhesion on the filler surfaces [26].

The relation between elongation at break and clay loading is illustrated in Figure 11. The addition of 1\% Nanomer PGV significantly increases the elongation at break of PLA/PCL blends from $1.82 \mathrm{~mm}$ to $4.30 \mathrm{~mm}$ with the increment around $136.26 \%$. However, the elongation at break of PLA/PCL blends decrease when Montmorillonite K10 is added. When higher amount of clay added into the blends, the elongation at break decreases for both clay. This might due to existence of large agglomerates which makes composites become more brittle. From the results obtained, it can be concluded that hydrophilicNanomer PGV makes PLA/PCL blends more flexible which might due to hydrophilic clay more compatible to blends.

3.2.5. Flexural Properties. Flexural Strength of PLA/PCL/clay composites are shown in Figure 12. Addition of 1\% Montmorillonite $\mathrm{K} 10$ and 1\% Nanomer PGV increase the flexural strength of blends from $42.523 \mathrm{MPa}$ to $48.645 \mathrm{MPa}$

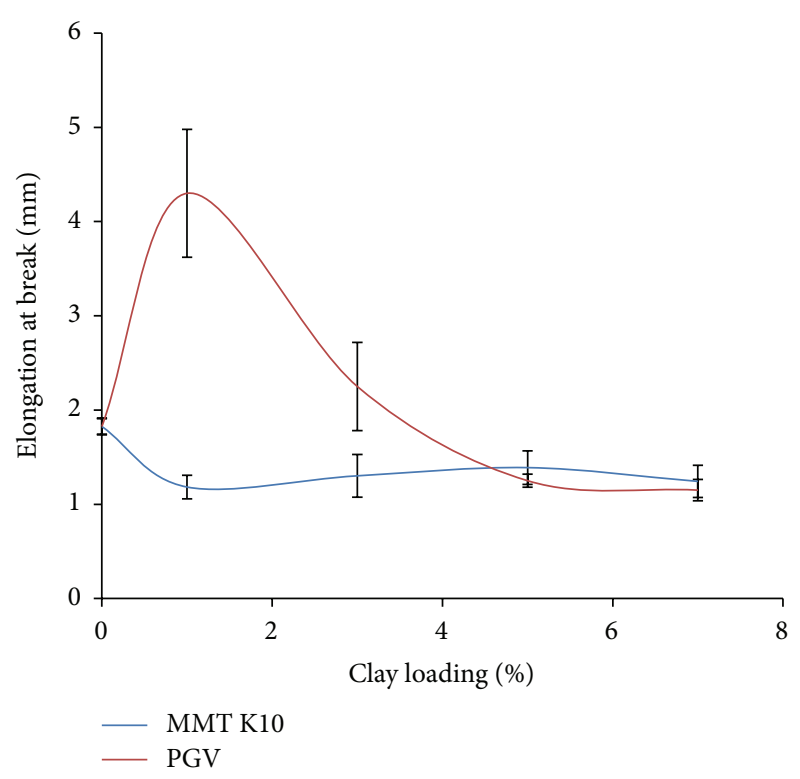

FIGURE 11: Elongation at break of PLA/PCL/clay nanocomposites.

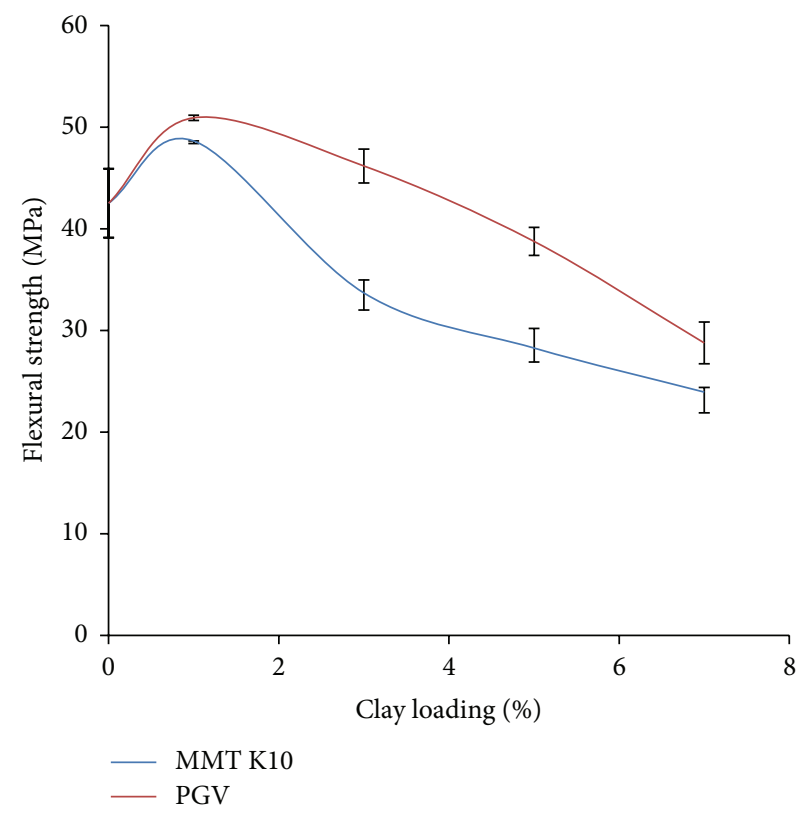

FIGURE 12: Flexural strength of PLA/PCL/clay nanocomposites.

and $50.930 \mathrm{MPa}$, respectively. When higher amount of clay incorporated into the blend, flexural strength decreases. The overall flexural strength of Nanomer PGV composites is higher than Montmorillonite K10. This might due to better interfacial adhesion between matrix and filler which will improve stress transfer from matrix to filler resulting higher values of flexural strength. Existence of agglomerates when higher amount of clay is added reduces flexural strength of composites.

Figure 13 illustrated the flexural modulus of the composites where Montmorillonite K10 composites shows higher value of flexural modulus than Nanomer PGV composites. 


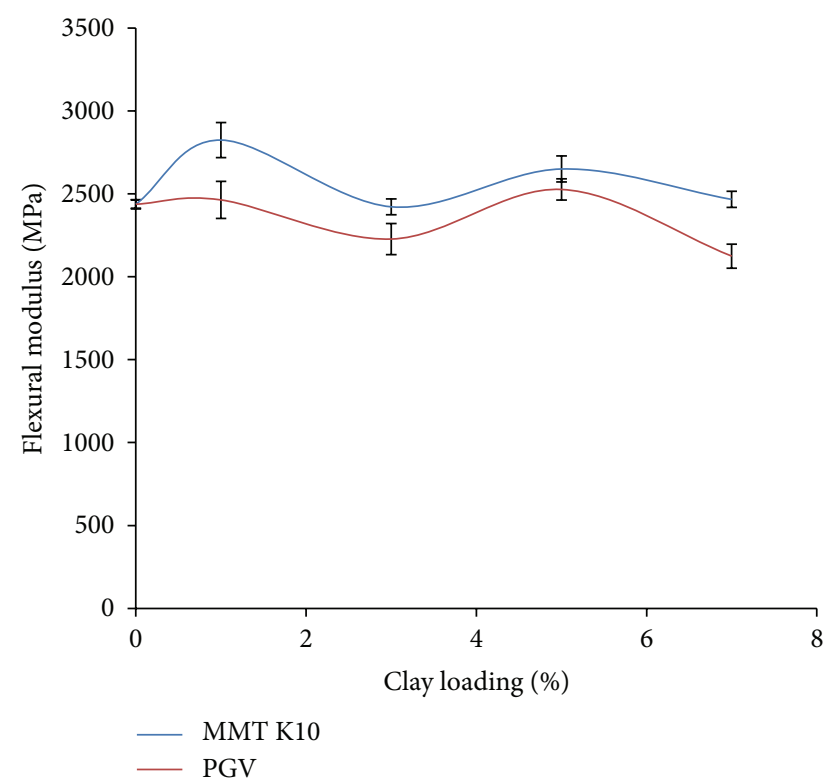

FIGURE 13: Flexural modulus of PLA/PCL/clay nanocomposites.

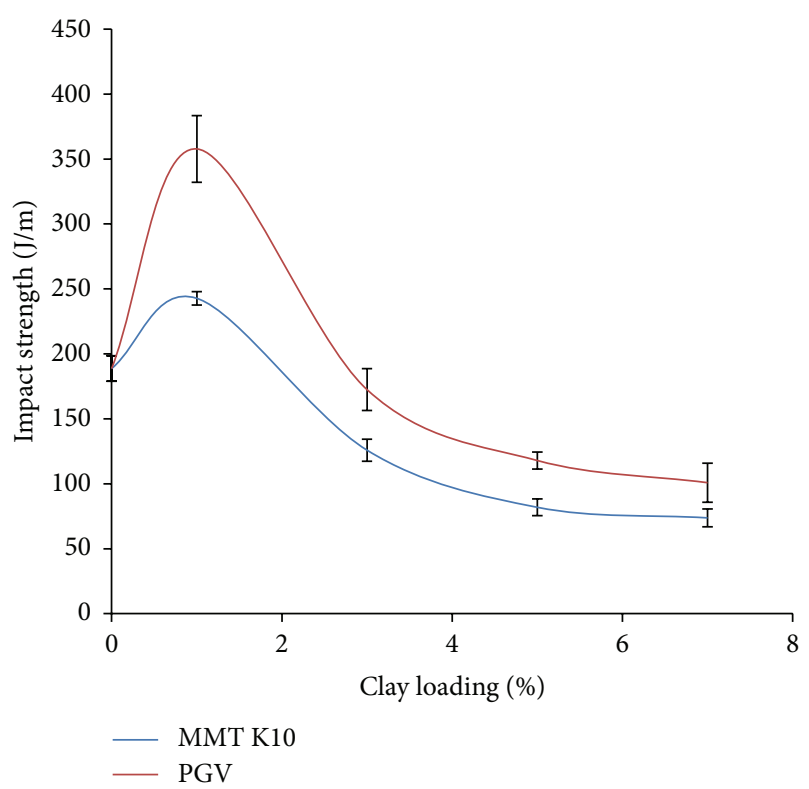

FIGURE 14: Impact strength of PLA/PCL/clay nanocomposites.

Montmorillonite K10 improves flexural modulus of blends from $2437.66 \mathrm{MPa}$ to $2824.50 \mathrm{MPa}$ while Nanomer PGV improves flexural modulus to $2463.00 \mathrm{MPa}$. The inherent stiffness of Montmorillonite K10 may positively contribute to the overall stiffness of the composites which increase the flexural modulus of composites.

3.2.6. Izod Impact Resistance. The relation between impact strength and clay loading is illustrated in Figure 14. When 1\% of Nanomer PGV was added into matrix, the impact strength increase from $188.70 \mathrm{~J} / \mathrm{m}$ to $357.78 \mathrm{~J} / \mathrm{m}$ with the increment about $89.61 \%$. The addition of $1 \%$ Montmorillonite K10 also

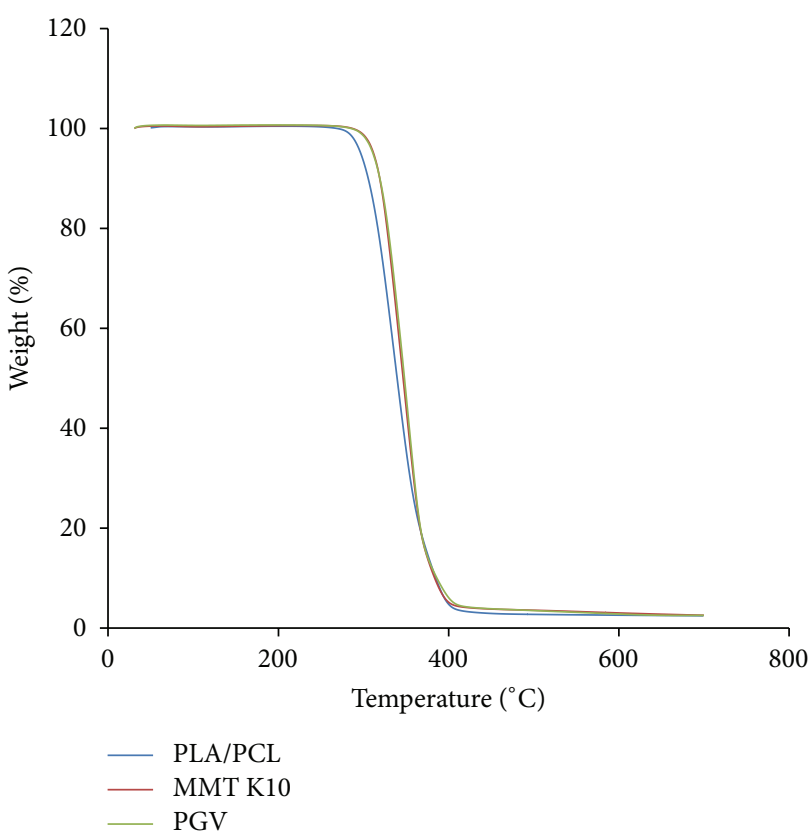

FIGURE 15: TG thermogram of PLA/PCL blends and its clay nanocomposites.

increase the impact strength of matrix from $188.70 \mathrm{~J} / \mathrm{m}$ to $242.75 \mathrm{~J} / \mathrm{m}$ (28.64\%). When excess of Nanomer PGV and Montmorillonite K10 added into matrix, the impact strength of matrix decrease, respectively. The overall impact strength of Nanomer PGV composites are higher than Montmorillonite K10 composites. Better interfacial adhesion between clay with matrix at high-aspect ratio of clay ( $1 \mathrm{wt} \%)$ resulting better stress transfer between matrix and clay which improve impact strength of the matrix.

3.2.7. Thermogravimetric Analysis (TGA). Figures 15 and 16 illustrated the TG and DTG thermogram of PLA/PCL blends and PLA/PCL/clay composites. The PLA/PCL blend shows onset temperature of $248^{\circ} \mathrm{C}$ is increase to $259^{\circ} \mathrm{C}$ and $258^{\circ} \mathrm{C}$ with maximum degradation temperature at $417^{\circ} \mathrm{C}$ and $415^{\circ} \mathrm{C}$ when clay Montmorillonite K10 and Nanomer PGV incorporated into the blend, respectively. Therefore, the incorporation of clay into polymer matrix successfully improves thermal stability of PLA/PCL blends.

The improvement in thermal stability due to clay can hinder the permeability of volatile degradation products out of the materials. The dispersed clay generates a barrier which delays the release of thermal degradation products in comparison the neat polymer [27]. Various theories models been proposed to explain the improvement in barrier properties of polymer/clay composites. Nielsen develop a theory to explain the improved barrier properties of polymer-clay composites which focuses on a tortuous path around the clay plates, forcing the gas permeant to travel a longer path to diffuse through the film. According to the theory, the increase in path length is a function of the high-aspect ratio of the clay filler and the volume percentage of the filler in the composite [28]. However, many deviations on Nielsen's theory can be 


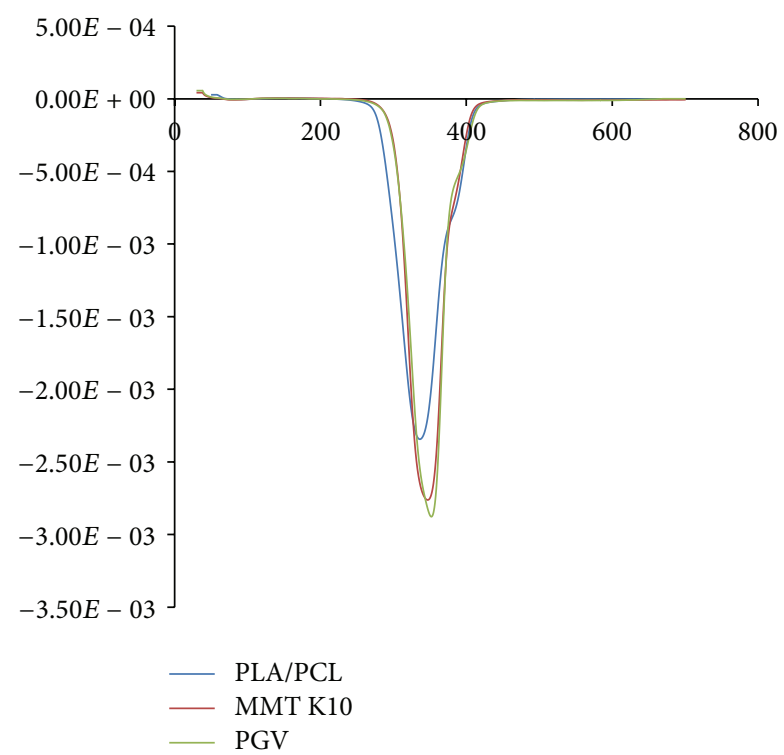

Figure 16: DTG thermogram of PLA/PCL blends and its clay nanocomposites.

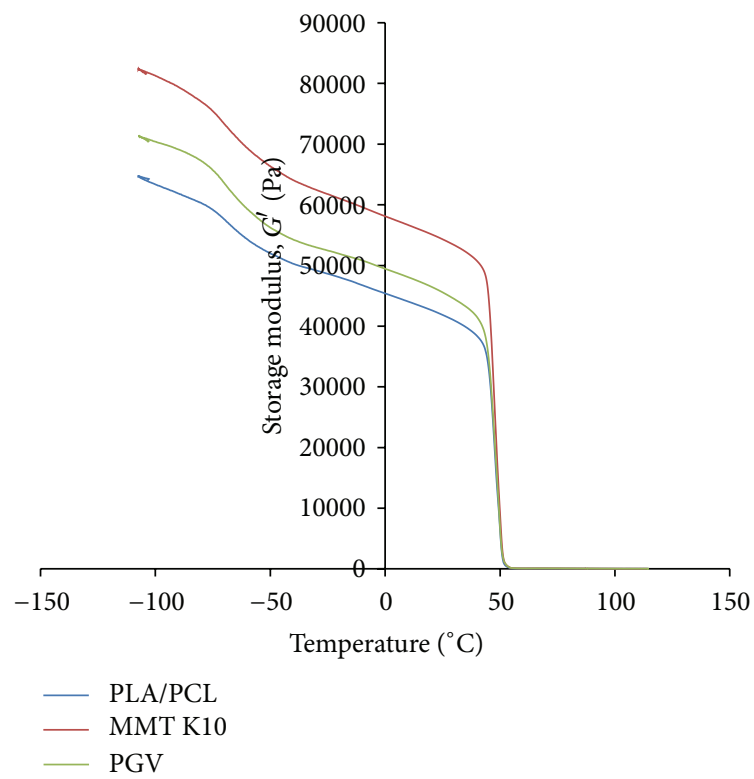

FIGURE 17: Storage modulus of PLA/PCL blends and its clay nanocomposites.

explained by factors such as less than complete exfoliation or poor orientations [29]. Beall proposed a new model which provides a correction factor applicable to Nielsen's model. In this model, polymer clay interface acts as a governing factor in addition to the tortuous path [30].

3.2.8. Dynamic Mechanical Analysis (DMA). The storage modulus $\left(G^{\prime}\right)$ of PLA/PCL and PLA/PCL/clay composite are shown in Figure 17. The incorporation of all clay increase the $G^{\prime}$ of PLA/PCL blends where clay Montmorillonite K10 shows highest increment of $G^{\prime}$. The $G^{\prime}$ results shows agreement with the tensile modulus results as Montmorillonite

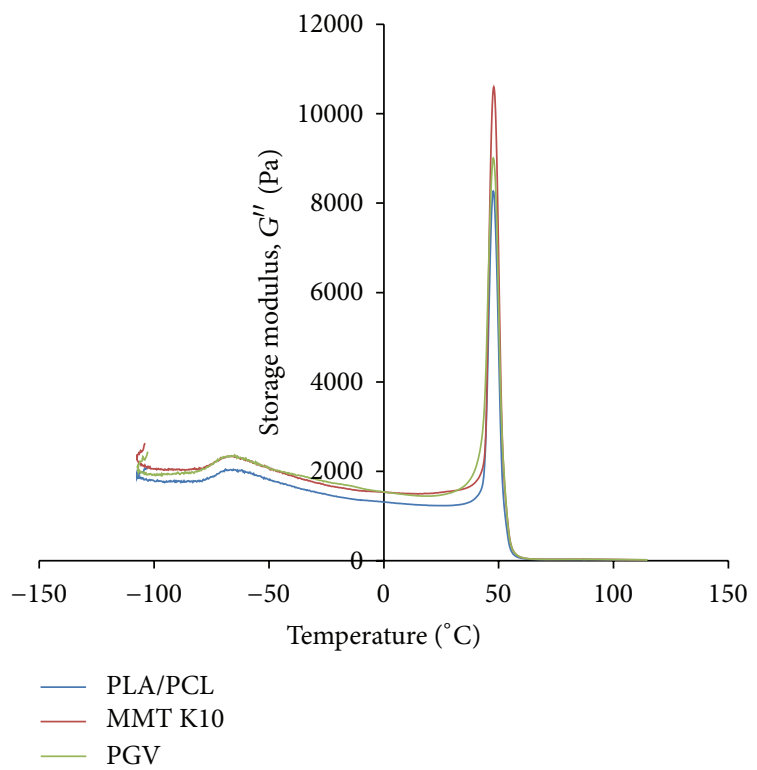

FIGURE 18: Loss modulus of PLA/PCL blends and its clay nanocomposites.

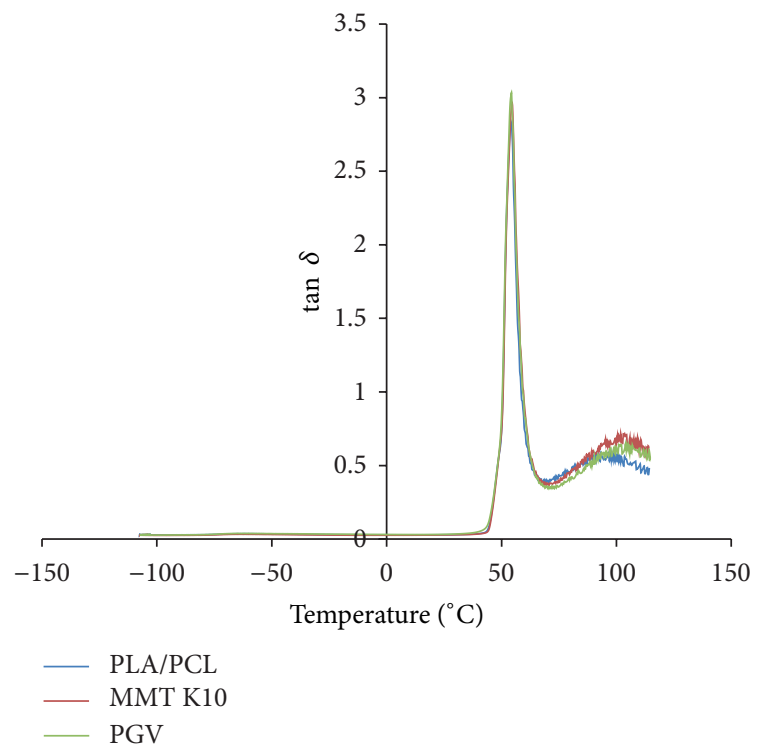

FIGURE 19: $\tan \delta$ of PLA/PCL blends and its clay nanocomposites.

K10 composites shows highest tensile modulus. The addition of clay show considerable effect on the elastic properties of polymer matrix. The increment of $G^{\prime}$ indicate that the incorporation of clay induces reinforcement effects of the matrix due to high dispersion and compatibility of matrix with fillers [31].

Figure 18 shows loss modulus $\left(G^{\prime \prime}\right)$ of PLA/PCL and PLA/PCL/clay composite. The peak intensity of $G^{\prime \prime}$ represents the melt viscosity of the polymer. The incorporation of both clays enhances melt viscosity of the composites. This is due to well-separated high-aspect ratio of silicate platelets increase the viscosity of the melt [32]. The increment of melt 


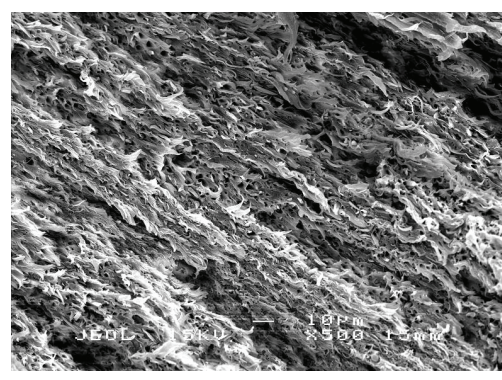

(a)

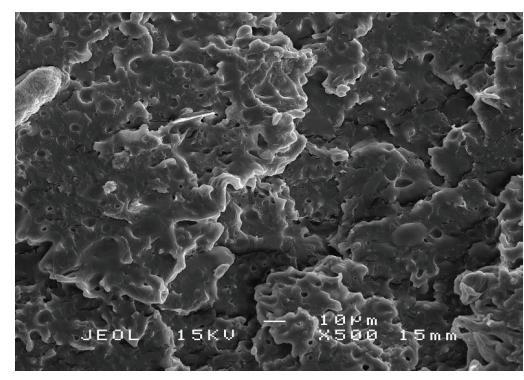

(b)

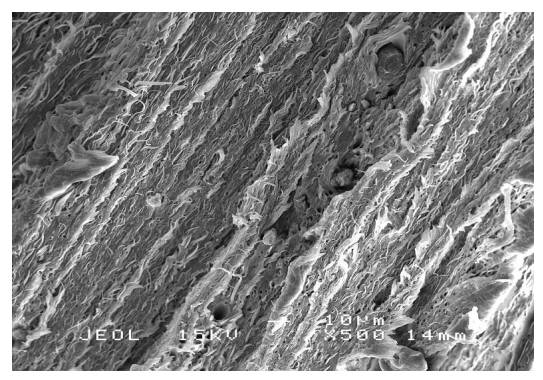

(c)

FIGURE 20: SEM micrograph of (a) PLA/PCL, (b) PLA/PCL/1 wt\% Montmorillonite K10, and (c) PLA/PCL/1 wt\% Nanomer PGV.

viscosity been assigned to the expansion and delamination of clay layers and structure formation between the layers due to strong hydrogen bond interaction at the edge to edge and edge to face contacts which restrict the movement of polymer chain [33]. Both of the clay composites exhibits two peak indicate $T_{g}$ of PLA and PCL in composites which proof that the composites is immiscible. The presence of clay Nanomer PGV slightly shift $T_{g}$ of blends from $-68.8^{\circ} \mathrm{C}$ to $-64.9^{\circ} \mathrm{C}$ at PCL region and also from $47.8^{\circ} \mathrm{C}$ to $47.5^{\circ} \mathrm{C}$ at PLA region suggest that the presence of clay slightly compatibilizer the PLA/PCL blends. The incorporation of clay Montmorillonite K10 also shifts $T_{g}$ of blends at PCL region to $-67.0^{\circ} \mathrm{C}$ but shows no shifting of $T_{g}$ at PLA region.

The loss factor $(\tan \delta$ ) of PLA/PCL and PLA/PCL/clay composite are illustrated in Figure 19. The sharp peak around $48^{\circ} \mathrm{C}$ for the PLA/PCL blends and PLA/PCL/clay composites corresponds to rapid storage energy loss. A small peak at around $90^{\circ} \mathrm{C}$ might due to density modulation preceding the formation of a precrystallization phase of PLA in composites [34]. The area underneath $\tan \delta$ peak indicates the damping ability of materials. The area underneath $\tan \delta$ peak shows that PLA/PCL blends and PLA/PCL/clay composites have also similar area which indicated that they possessed almost similar damping abilities.

3.2.9. Scanning Electron Microscopy (SEM). SEM micrograph of fractured surface of (a) PLA/PCL, (b) PLA/PCL/1 wt\% Montmorillonite K10, and (c) PLA/PCL/1 wt\% Nanomer PGV are show in Figure 20 at magnification of 500X. Figure 20(a) shows that PLA/PCL blends formed continuous phase, stretchable before it breaks with some small void on surface as PLA/PCL are immiscible polymer blends. When $1 \mathrm{wt} \%$ Montmorillonite K10 added to the blends, matrix is not well stretched before it breaks and continuous phase formed with some void present on the surface (Figure 20(b)) which indicated incompatibility of Montmorillonite K10 with the matrix. As shown in Figure 20(c), PLA/PCL/Nanomer PGV composites showed more homogeneous, well stretched before breaks and single phase morphology which indicates good interaction of components in the matrix.

\section{Conclusion}

The incorporation of hydrophilic clay Nanomer PGV successfully enhance mechanical properties of PLA/PCL blends and makes it become more flexible while the addition of clay Montmorillonite K10 makes PLA/PCL blends become stiffer. FTIR results revealed formation of hydrogen bond between hydrophilic clay with the matrix. XRD results show that the addition of Nanomer PGV increase of the basal spacing of the composites compared to the corresponding neat clay which implies that the PLA/PCL chains might be intercalated into the clay matrix after mixing but there is no clear evidence from TEM micrographs to support the formation of intercalated types of nanocomposites. For Montmorillonite K10, XRD result shows little shifting of diffraction peak of Montmorillonite K10 in composites while TEM results shows that the formation agglomerates throughout polymer matrix indicate phase separated microcomposites, form when Montmorillonite K10 was added to the blend. SEM micrographs revealed that incompatibility of Montmorillonite K10 with the matrix while the addition of Nanomer PGV in blends influence the morphology become more homogeneous and single phase morphology. TGA showed that the presence of both type of clay improve thermal stability of blends. DMA show the addition of clay increase storage modulus and the presence of clay Nanomer PGV slightly shift two $T_{g}$ of blends become closer suggest that the presence of clay slightly compatibilizer the PLA/PCL blends.

\section{Conflict of Interests}

The authors declare that there is no conflict of interest with any financial organization regarding the materials discussed in the paper.

\section{Acknowledgments}

The authors would like to thank the Research University Grant Scheme (RUGS), UPM, for their financial support. All technical staffs in the Department of Chemistry, Faculty of Science, University Putra Malaysia, are greatly acknowledged for their kind assistance.

\section{References}

[1] L. S. Nair and C. T. Laurencin, "Biodegradable polymers as biomaterials," Progress in Polymer Science, vol. 32, no. 8-9, pp. 762798, 2007. 
[2] A. C. Vieira, A. T. Marques, R. M. Guedes, and V. Tita, "Material model proposal for biodegradable materials," Procedia Engineering, vol. 10, pp. 1597-1602, 2011.

[3] B. Gupta, N. Revagade, and J. Hilborn, "Poly(lactic acid) fiber: an overview," Progress in Polymer Science, vol. 32, no. 4, pp. 455482, 2007.

[4] H. Balakrishnan, A. Hassan, M. U. Wahit, A. A. Yussuf, and S. B. A. Razak, "Novel toughened polylactic acid nanocomposite: mechanical, thermal and morphological properties," Materials and Design, vol. 31, no. 7, pp. 3289-3298, 2010.

[5] H. Fukuzaki, M. Yoshida, M. Asano et al., "Synthesis of lowmolecular-weight copoly(l-lactic acid/E-caprolactone) by direct copolycondensation in the absence of catalysts, and enzymatic degradation of the polymers," Polymer, vol. 31, no. 10, pp. 20062014, 1990.

[6] D. W. Grijpma and A. J. Pennings, “(Co)polymers of L-lactide, 1. Synthesis, thermal properties and hydrolytic degradation," Macromolecular Chemistry and Physics, vol. 195, no. 5, pp. 16331647, 1994.

[7] H. Chen, M. Pyda, and P. Cebe, "Non-isothermal crystallization of PET/PLA blends," Thermochimica Acta, vol. 492, no. 1-2, pp. 61-66, 2009.

[8] T. Yokohara and M. Yamaguchi, "Structure and properties for biomass-based polyester blends of PLA and PBS," European Polymer Journal, vol. 44, no. 3, pp. 677-685, 2008.

[9] V. S. G. Silverajah, N. A. Ibrahim, W. W. M. Z. Yunus, H. A. Hassan, and C. B. Woei, "A comparative study on the mechanical, thermal and morphological characterization of poly(lactic acid)/epoxidized palm oil blend," International Journal of Molecular Sciences, vol. 13, no. 5, pp. 5878-5898, 2012.

[10] Y. Phuphuak and S. Chirachanchai, "Simple preparation of multi-branched poly(l-lactic acid) and its role as nucleating agent for poly(lactic acid)," Polymer, vol. 54, no. 2, pp. 572-582, 2013.

[11] S. Ochi, "Mechanical properties of kenaf fibers and kenaf/PLA composites," Mechanics of Materials, vol. 40, no. 4-5, pp. 446452, 2008.

[12] J.-W. Rhim, S.-I. Hong, and C.-S. Ha, “Tensile, water vapor barrier and antimicrobial properties of PLA/nanoclay composite films," LWT-Food Science and Technology, vol. 42, no. 2, pp. 612-617, 2009.

[13] M. A. Woodruff and D. W. Hutmacher, "The return of a forgotten polymer-polycaprolactone in the 21st century," Progress in Polymer Science, vol. 35, no. 10, pp. 1217-1256, 2010.

[14] J.-T. Yeh, C.-J. Wu, C.-H. Tsou et al., "Study on the crystallization, miscibility, morphology, properties of poly(lactic acid)/poly( $\varepsilon$-caprolactone) blends," Polymer, vol. 48, no. 6, pp. 571-578, 2009.

[15] D. Wu, Y. Zhang, M. Zhang, and W. Zhou, "Phase behavior and its viscoelastic response of polylactide/poly( $\varepsilon$-caprolactone) blend," European Polymer Journal, vol. 44, no. 7, pp. 2171-2183, 2008.

[16] F. Tuba, L. Oláh, and P. Nagy, "Characterization of reactively compatibilized poly(d,l-lactide)/poly( $\varepsilon$-caprolactone) biodegradable blends by essential work of fracture method," Engineering Fracture Mechanics, vol. 78, no. 17, pp. 3123-3133, 2011.

[17] W. H. Hoidy, M. B. Ahmad, E. A. J. Al-Mulla, and N. A. B. Ibrahim, "Preparation and characterization of polylactic acid/polycaprolactone clay nanocomposites," Journal of Applied Sciences, vol. 10, no. 2, pp. 97-106, 2010.

[18] J. Madejová and P. Komadel, "Baseline studies of the clay minerals society source clays: infrared methods," Clays and Clay Minerals, vol. 49, no. 5, pp. 410-432, 2001.

[19] R. Ravisankar, S. Kiruba, P. Eswaran, G. Senthilkumar, and A. Chandrasekaran, "Mineralogical characterization studies of ancient potteries of Tamilnadu, India by FT-IR spectroscopic technique," E-Journal of Chemistry, vol. 7, no. 1, pp. S185-S190, 2010.

[20] R. R. Tiwari, K. C. Khilar, and U. Natarajan, "Synthesis and characterization of novel organo-montmorillonites," Applied Clay Science, vol. 38, no. 3-4, pp. 203-208, 2008.

[21] A. K. Nikolaidis, D. S. Achilias, and G. P. Karayannidis, "Effect of the type of organic modifier on the polymerization kinetics and the properties of poly(methyl methacrylate)/organomodified montmorillonite nanocomposites," European Polymer Journal, vol. 48, no. 2, pp. 240-251, 2012.

[22] N. A. Ibrahim, B. W. Chieng, and W. M. Z. Wan Yunus, "Morphology, thermal and mechanical properties of biodegradable poly(butylene succinate)/poly(butylene adipate-co-terephthalate)/clay nanocomposites," Polymer, vol. 49, no. 15, pp. 1571-1580, 2010.

[23] H. Essawy and D. El-Nashar, "The use of montmorillonite as a reinforcing and compatibilizing filler for NBR/SBR rubber blend," Polymer Testing, vol. 23, no. 7, pp. 803-807, 2004.

[24] S. N. Sathe, G. S. Srinivasa Rao, K. V. Rao, and S. Devi, "The effect of composition on morphological, thermal, and mechanical properties of polypropylene/nylon-6/polypropylene-g-butyl acrylate blends," Polymer Engineering and Science, vol. 36, no. 19, pp. 2443-2450, 1996.

[25] J. Wang and R. Pyrz, "Prediction of the overall moduli of layered silicate-reinforced nanocomposites-part I: basic theory and formulas," Composites Science and Technology, vol. 64, no. 7-8, pp. 925-934, 2004.

[26] Z. Yu, J. Yin, S. Yan, Y. Xie, J. Ma, and X. Chen, "Biodegradable poly(l-lactide)/poly( $\varepsilon$-caprolactone)-modified montmorillonite nanocomposites: preparation and characterization," Polymer, vol. 48, no. 21, pp. 6439-6447, 2007.

[27] T. Agag, T. Koga, and T. Takeichi, "Studies on thermal and mechanical properties of polyimide-clay nanocomposites," Polymer, vol. 42, no. 8, pp. 3399-3408, 2001.

[28] C. Silvestre, D. Duraccio, and S. Cimmino, "Food packaging based on polymer nanomaterials," Progress in Polymer Science, vol. 36, no. 12, pp. 1766-1782, 2011.

[29] K. Majeed, M. Jawaid, A. Hassan et al., "Potential materials for food packaging from nanoclay/natural fibres filled hybrid composites," Materials \& Design, vol. 46, pp. 391-410, 2013.

[30] D. Adame and G. W. Beall, "Direct measurement of the constrained polymer region in polyamide/clay nanocomposites and the implications for gas diffusion," Applied Clay Science, vol. 42, no. 3-4, pp. 545-552, 2009.

[31] K. Fukushima, D. Tabuani, and G. Camino, "Nanocomposites of PLA and PCL based on montmorillonite and sepiolite," Materials Science and Engineering C, vol. 29, no. 4, pp. 1433-1441, 2009.

[32] S. Boucard, J. Duchet, J. F. Gérard, P. Prele, and S. Gonzalez, "Processing of polypropylene-clay hybrids," Macromolecular Symposia, vol. 194, no. 1, pp. 241-246, 2003. 
[33] X. Fu and S. Qutubuddin, "Polymer-clay nanocomposites: exfoliation of organophilic montmorillonite nanolayers in polystyrene," Polymer, vol. 42, no. 2, pp. 807-813, 2001.

[34] F. Cock, A. A. Cuadri, M. García-Morales, and R. Partai, “Thermal, rheological and microstructural characterisation of commercial biodegradable polyesters," Polymer Testing, vol. 32, no. 4, pp. 716-723, 2013. 

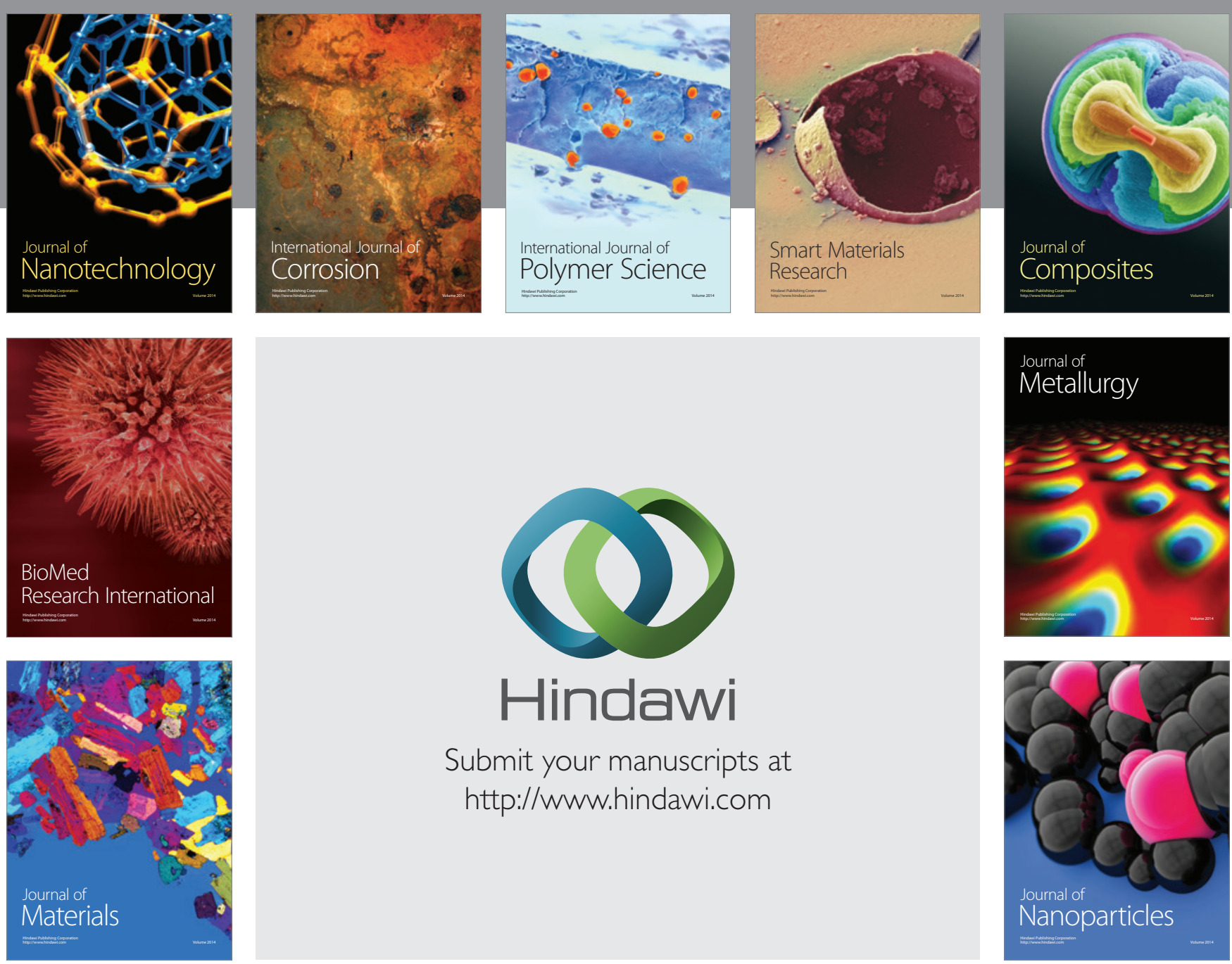

Submit your manuscripts at http://www.hindawi.com
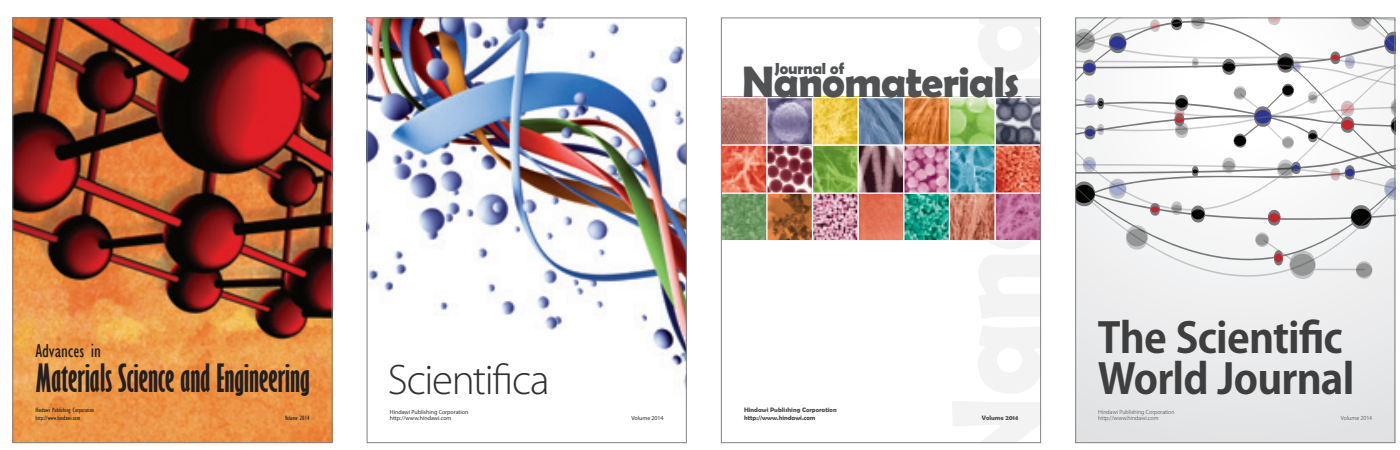

\section{The Scientific World Journal}
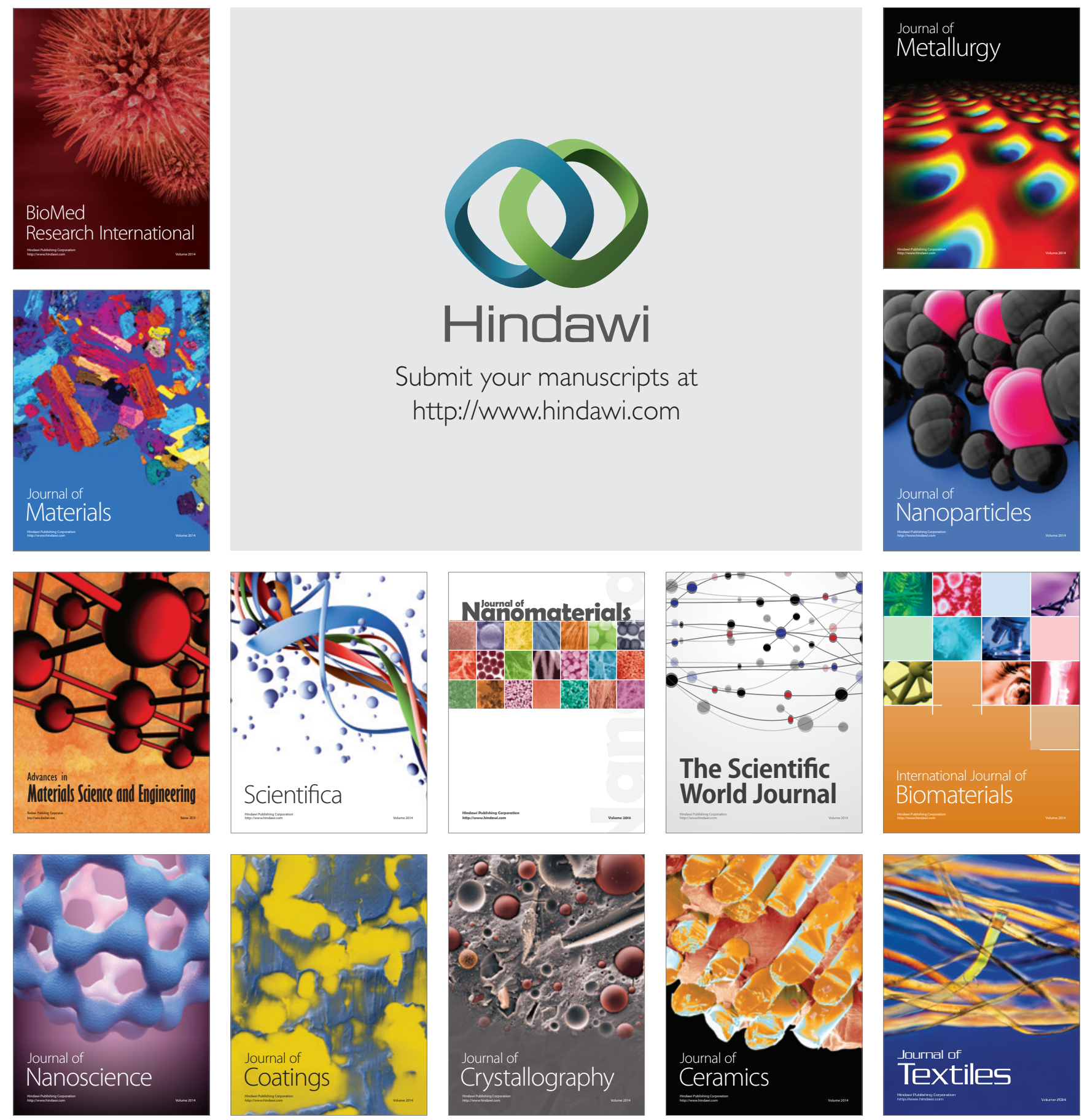